\title{
Genomic copy number alterations associated with the early brain metastasis of non-small cell lung cancer
}

\author{
HYE WON LEE ${ }^{1,2,4^{*}}$, HO JUN SEOL ${ }^{1,2^{*}}$, YOON-LA CHOI $^{3 *}$, HYUN JUNG JU $^{3}$, \\ KYEUNG MIN JOO ${ }^{5,6}$, YOUNG-HYEH KO ${ }^{3}$, JUNG-IL LEE ${ }^{2}$ and DO-HYUN NAM ${ }^{1,2}$
}

\begin{abstract}
${ }^{1}$ Cancer Stem Cell Research Center, Departments of ${ }^{2}$ Neurosurgery and ${ }^{3}$ Pathology, Institute for Refractory Cancer Research, Samsung Medical Center, Sungkyunkwan University School of Medicine, Seoul 135-710; ${ }^{4}$ Samsung Advanced Institute for Health Sciences and Technology (SAIHST), Sungkyunkwan University; ${ }^{5}$ Department of Anatomy, Sungkyunkwan University School of Medicine, Seoul 135-710; ${ }^{6}$ Center for Molecular Medicine, Samsung Biomedical Research Institute, Suwon 440-746, Republic of Korea
\end{abstract}

Received June 19, 2012; Accepted August 16, 2012

DOI: 10.3892/ijo.2012.1663

\begin{abstract}
Frequent early development of systemic metastasis leads to unfavourable clinical prognosis of non-small cell lung cancer (NSCLC). Although brain metastasis (BM) contributes significantly to morbidity and mortality of NSCLC, relevant driver mechanisms are largely unknown. To elucidate genetic alterations associated with early BM of NSCLC, we retrospectively collected 18 NSCLC cases with BM [12 adenocarcinomas (ADC) and 6 squamous cell carcinomas (SQCC)] whose surgical tissues of both primary and brain metastatic tumors were preserved as formaldehyde-fixed and paraffinembedded (FFPE) pathological samples. When chromosomal copy number alterations (CNA) of those FFPE samples were analysed by the Molecular Inversion Probe (MIP) technology, the most frequent CNAs detected in primary lung ADCs were gains of 3q, 5p, 5q, 6p, 8q, 9p, 11p, 15q, 17q and losses of 10q and $22 q$ whereas primary lung SQCCs revealed gains in $4 q$ and $12 \mathrm{q}$ and loss in 9q. In particular, when comparative MIP was performed in primary $12 \mathrm{ADCs}$ depending on the pattern of $\mathrm{BM}$ to uncover predetermining signatures that can predict the risk of BM, selectively amplified regions of primary lung ADCs (5q35, 10q23 and 17q23-24) were identified as significantly associated with the development of early BM within 3 months after first diagnosis of primary tumors. Those regions
\end{abstract}

Correspondence to: Dr Do-Hyun Nam or Dr Jung-Il Lee, Department of Neurosurgery, Institute for Refractory Cancer Research, Samsung Medical Center, Sungkyunkwan University School of Medicine, 50 Irwon-dong, Gangnam-gu, Seoul 135-710, Republic of Korea

E-mail: nsnam@skku.edu

E-mail: jilee@skku.edu

*Contributed equally

Key words: non-small cell lung cancer, brain metastasis, chromosomal aberration, Molecular Inversion Probe technology, prognostic marker harbour several candidate genes including NeurL1B, ACTA2, FAS and ICAM2. Although more validation is needed, the genetic signatures elucidated in this study help to identify useful molecular markers defining an NSCLC patient subgroup at risk of early BM, guiding therapeutic decisions.

\section{Introduction}

Non-small cell lung cancer (NSCLC) including adenocarcinoma (ADC) and squamous cell carcinoma (SQCC) accounts for approximately $80-90 \%$ of all diagnosed lung cancers $(1,2)$. Despite recent advances in understanding complex pathophysiology, uncovering predictive/prognostic markers, and developing novel technologies to aid diagnosis/treatment decision, NSCLC is still the major determinant of overall cancer mortality (3-7). The 5-year survival rate was $15 \%$ across all stages of the diseaseranging from $2.8 \%$ for patients with distant metastases to nearly $50 \%$ for those presenting with local disease. Because NSCLC is a heterogeneous disease entity, the accurate stratification of the patients with high risk of developing recurrence or distant metastasis would improve final prognosis.

While the brain is a major site of relapse contributing to the unfavorable prognosis of the NSCLC, the relevant molecular mechanisms are largely unknown. Lung ADC is known to establish distant macrometastasis within months of initial diagnosis (8-10). This short latency implies that metastatic competence would result from early oncogenic events that drive primary tumor growth rather than late-arising, rare genomic alterations specific for metastasis (11). Therefore, defining consistent chromosomal changes in the primary NSCLC could help to identify metastasis-specific signatures. Molecular inversion probe (MIP) technology is a high-throughput genotyping capable of providing copy number measurements with high precision and specificity, proven to be a valid array for analyzing copy number in formaldehyde-fixed and paraffin-embedded (FFPE) samples (12-14). In this study, to delineate prognostic markers to stratify NSCLC patients at higher risk for developing brain metastasis (BM) and novel therapeutic candidates targeting BM, the patterns of copy number alterations (CNA) in primary lung NSCLC FFPE samples were analyzed by MIP technology. 


\section{Materials and methods}

Pathology samples from NSCLS patients with brain metastases. Our study was reviewed and approved by the Institutional Review Board of the Samsung Medical Center (Seoul, Korea). All pathology samples and clinical data were obtained with written informed consent according to the institutional regulations. In the pathology database of the Samsung Medical Center (1994.12-2010.7), 160 NSCLC brain metastasis patients were identified. From them, 36 cases were selected; exclusion criteria, the biopsy of primary lung cancer without brain metastasis sample; inclusion criteria, harbouring visible tumors. A total of 37 formaldehyde-fixed and paraffin-embedded (FFPE) pathology samples were analyzed by this MIP analysis including 3 normal lung and 5 brain controls as follows: 20 ADCs of 8 paired cases (lung cancer and BM derived from same patient) and 4 only lung cancer cases; 9 SQCCs of 3 paired cases and 3 only lung cancers. Normal lung and brain tissues were obtained from the patients with other benign diseases.

All NSCLC patients were classified according to the standard World Health Organization (WHO) histological typing of lung carcinomas and the TNM (tumor-node-metastasis) staging system of the International Union Against Cancer (UICC). Clinicopathological data including age, gender, tumor stage and treatment history were obtained by a review of the medical records. Sites of distant metastasis and disease recurrence after treatment were traced by serial computed tomography (CT), magnetic resonance imaging (MRI) and positron emission tomography (PET). BM was defined as synchronous when metastasis was detected within 3 months of the initial diagnosis of primary tumor. The others were defined as metachronous.

Isolation of genomic DNA. Genomic DNA (gDNA) was extracted from three 5- $\mu \mathrm{m}$-thick sections per FFPE block for each pathology sample. Deparaffinization and RNA extraction/ purification was performed using a QIAamp DNA FFPEITissue kit (Qiagen) according the proposed protocol. The only change to the standard protocol was to increase the proteinase $\mathrm{K}$ digestion time (overnight). Extracted gDNA was stored at $-20^{\circ} \mathrm{C}$, and DNA quantity was analyzed by a Quant-iT Picogreen dsDNA kit (Invitrogen).

Molecular inversion probe (MIP) assay and data analysis. The MIP assay was performed using the OncoScan ${ }^{\mathrm{TM}}$ FFPE Express 330K MIP platform (Affymetrix). The MIP assay was performed as described previously $(12,15)$. Briefly, gDNA samples (75 ng per each sample) were annealed with the 24,037 MIP probes ( $200 \mathrm{amol} / \mu 1$ per probe) in a $384-$ well plate on ice at $20^{\circ} \mathrm{C}$ for 4 minutes $(\mathrm{min})$, at $95^{\circ} \mathrm{C}$ for $5 \mathrm{~min}$, and then at $58^{\circ} \mathrm{C}$ overnight. The mixtures were circularized with the addition of $4 \mu 1$ of the appropriate nucleotide at $58^{\circ} \mathrm{C}$ for $10 \mathrm{~min}$ (gap-fill ligation). Un-circularized MIP probes and gDNA were eliminated by addition of $4 \mu \mathrm{l}$ of exonucleases $\left(37^{\circ} \mathrm{C}\right.$ for $15 \mathrm{~min}$ followed by heat inactivation). The circularized probes were linearized by restriction enzyme digest at $37^{\circ} \mathrm{C}$ for $15 \mathrm{~min}$, and then amplified using a universal primer for 18 cycles $\left[95^{\circ} \mathrm{C}\right.$ for 20 seconds (sec), $64^{\circ} \mathrm{C}$ for $40 \mathrm{sec}$, and $72^{\circ} \mathrm{C}$ for $10 \mathrm{sec}]$. For the labeling reaction, the amplified products were further amplified with the label primers for 10 cycles. The MIP polymerase chain reaction (PCR) products were mixed with hybridization cocktail, denatured, and hybridized to $30 \mathrm{~K}$ Universal Tag Arrays (Affymetrix) at $39^{\circ} \mathrm{C}$ for $16 \mathrm{~h}$ with two arrays for each allele. The hybridized arrays were washed on a standard Affymetrix fluidic station and stained with streptavidin-phycoerythrin (5 ng/ml, Invitrogen).

Copy number estimation was obtained from the barcode hybridization signals as described previously (12). The copy number changes of the NSCLCs were analyzed compared with the copy number of the normal non-neoplastic lung and brain samples. Data analysis including copy sum and copy contrast computation, allele ratio, sample normalization, data smoothing was performed by Nexus copy number analytics Version 5.1 Software (Biodiscovery), using algorithm SNP-FASST2 with sensitivity $\mathrm{p}<0.05$.

\section{Results}

Detailed clinicopathological data of the 18 NSCLC patients with BM (12 ADCs and 6 SQCCs) are summarized in Table I. The median age of the NSCLC patients at the initial diagnosis of the primary cancers was 55 years (range 33-72 years). Synchronous (metastasis within 3 months of the initial diagnosis of primary NSCLC) and metachronous (metastasis after 3 months of the initial diagnosis of primary NSCLC) BM were $6(33 \%)$ and 12 cases (67\%), respectively. Median time between initial diagnosis of primary tumors and onset of overall BM was 257.5 days (8.6 months). The median lag (range) till BM for synchronous tumors was $0(0-88)$ while for metachronous tumors the lag was 545 (180-2190) days.

Specific copy number alterations depending on distinct histologic-subtypes of non-small cell lung cancer. In this study, chromosomal aberration of 18 NSCLC lung samples (12 ADCs and 6 SQCCs) and 3 normal lung controls was analyzed by the MIP technology to identify chromosomal aberrations involved in the distinct pathogenesis. Common genomic aberrations were defined as continuous genomic regions where the average signal in tumors consistently and significantly differed from that of normal lung samples. Since there is growing evidence that lung ADC and SQCC have distinct oncogenic mutations and divergent therapeutic responses $(16,17), 12$ ADCs and 6 SQCCs were analyzed separately. A full view of the frequently detected significant chromosomal aberrations is presented in Fig. 1. The most frequent aberrations identified in primary ADCs ( $>40 \%$ of cases) were $3 q, 5 p, 5 q, 6 p, 8 q, 9 p$, $11 p, 15 q$ and $17 q$ for copy number gains and $10 q$ and $22 q$ for losses (Table II). On the other hand, primary SQCCs revealed frequent copy number gains in $4 \mathrm{q}$ and $12 \mathrm{q}$ and copy number loss in 9q (Table II). Previously, whole-genome array comparative genomic hybridization (aCGH) identified significantly different chromosomal signatures between two subtypes of the NSCLC (18). Compared with the previous results using different experimental techniques, similar patterns of CNAs were observed in this study, confirming the validity of the MIP technology (19-22). However, several studies demonstrated additional CNAs including gains of $1 \mathrm{q}$ and losses of $9 \mathrm{q}$ and $10 p$ in ADC and gains of $3 q, 7 p, 12 p$ and $20 q$ as well as losses of $2 q, 3 p, 16 p$ and $17 p$ in SQCC $(21,23-25)$.

Continuous somatic evolution eventually giving rise to overt metastasis revealed the metastasis-specific related genes that 


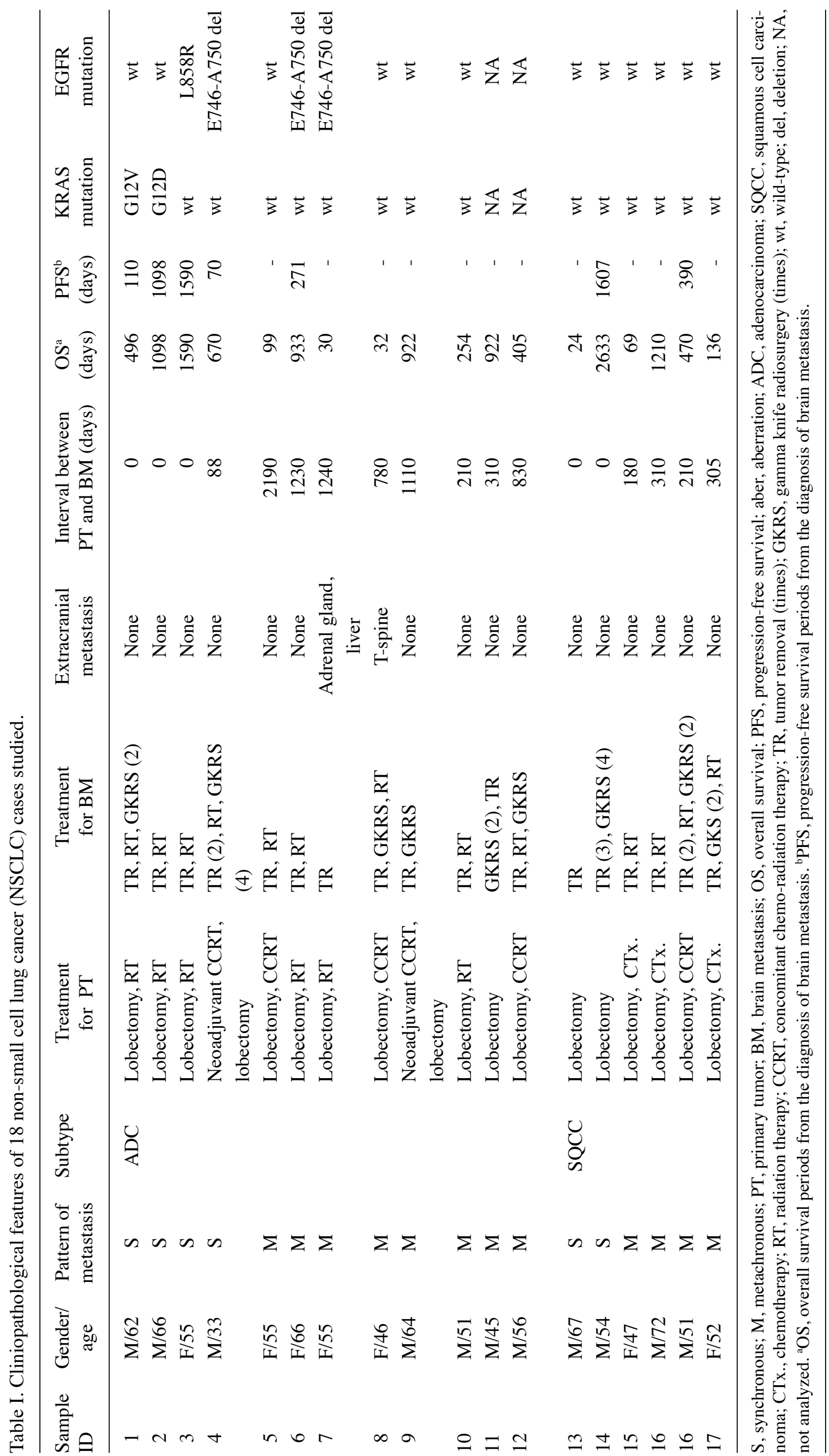



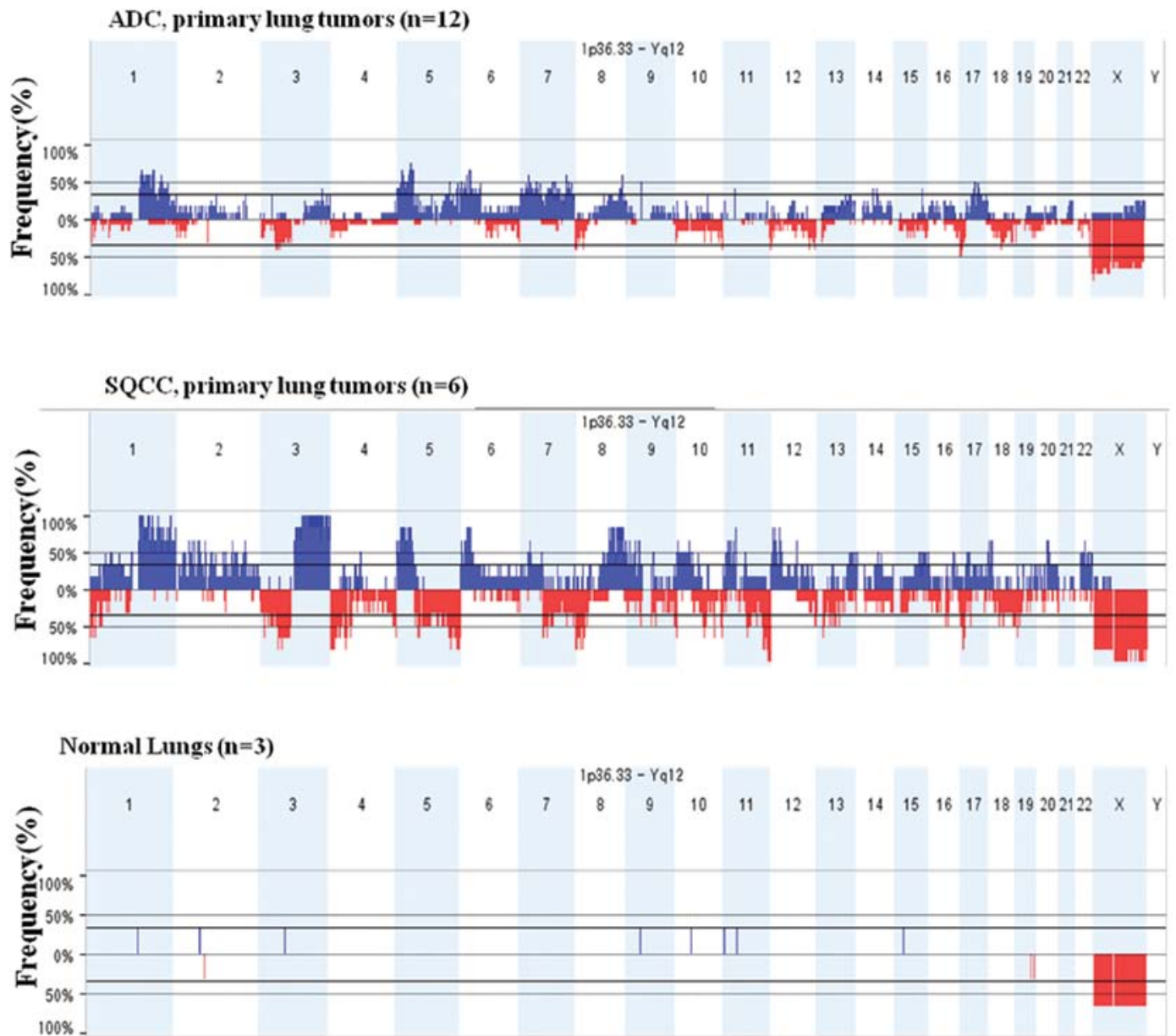

Figure 1. Copy number gains (blue) and losses (red) detected by MIP array in primary lung adenocarcinomas (ADCs, n=12) and squamous cell carcinomas (SQCCs, n=6). Frequencies of genome copy number gains and losses were plotted as a function of genome location with chromosomes 1pter to the left and chromosomes 22qter and $\mathrm{X}$ to the right. "ADC, adenocarcinoma; SQCC, squamous cell carcinoma.
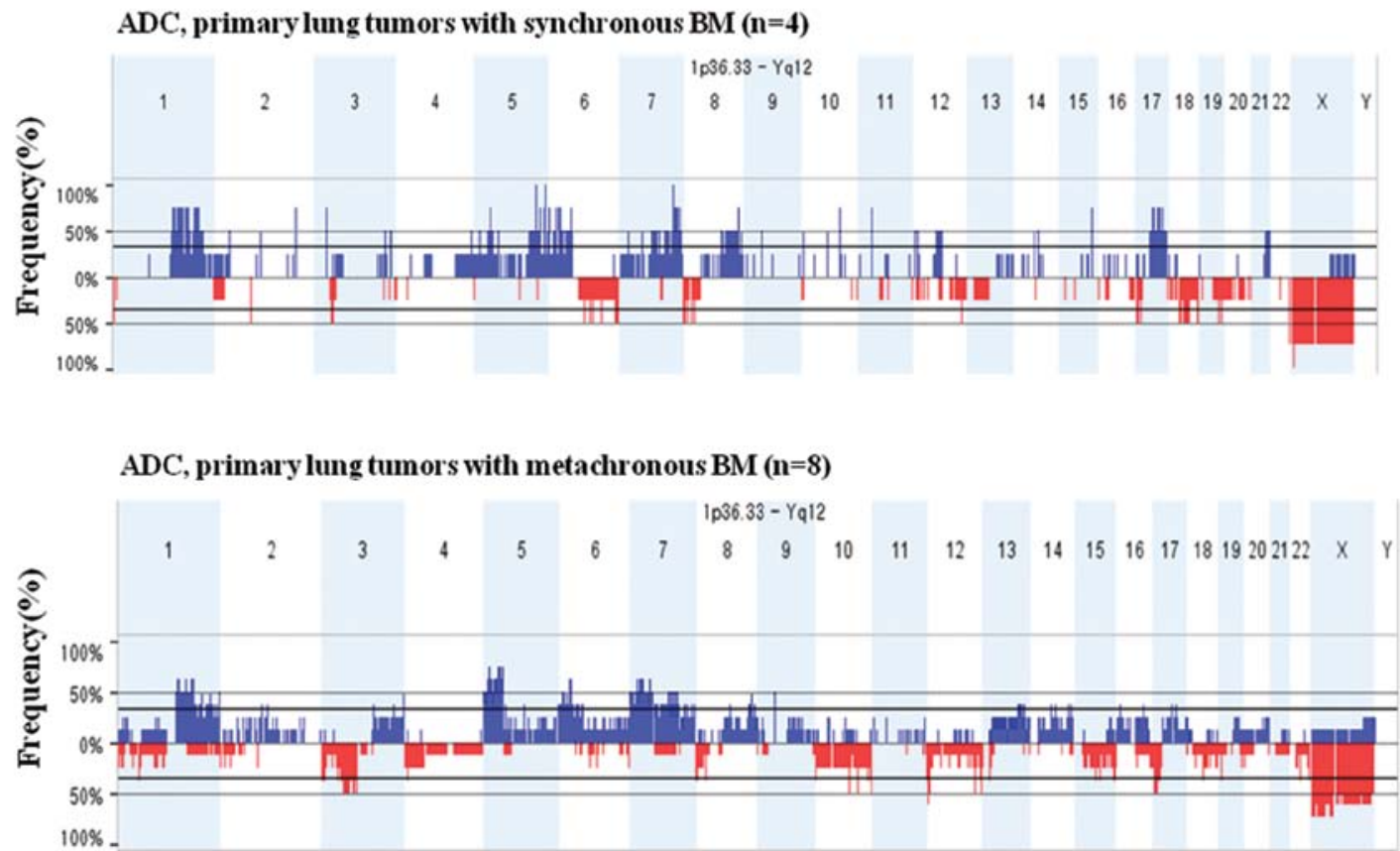

Figure 2. Differential chromosomal abnormalities among primary lung ADCs derived from the patients with synchronous $(\mathrm{n}=4)$ and metachronous $(\mathrm{n}=8)$ brain metastasis analyzed by MIP array. Frequencies of genome copy number gains and losses were plotted as a function of genome location with chromosomes 1pter to the left and chromosomes 22qter and $\mathrm{X}$ to the right. Blue and red columns indicate frequencies of tumors showing copy number gains and losses, respectively. *ADC, adenocarcinoma; BM, brain metastasis. 
Table II. Frequent regions of adenocarcinoma-specific and squamous cell carcinoma-specific copy number alteration.

\begin{tabular}{|c|c|c|c|c|c|}
\hline NSCLC subtype & Chromosomal aberration & Region (start site-end site) & Cytoband location & Frequency $\%$ & P-value \\
\hline \multirow{13}{*}{$\begin{array}{l}\text { Adenocarcinoma } \\
(\mathrm{n}=12)\end{array}$} & $\mathrm{CN}$ gain & $\operatorname{chr} 3: 173,271,977-173,427,105$ & $\mathrm{q} 26.31$ & 41.7 & 0.011 \\
\hline & $\mathrm{CN}$ gain & chr5:40,349,188-40,886,467 & p13.1 & 75 & 0.018 \\
\hline & $\mathrm{CN}$ gain & chr5:150,438,972-150,523,583 & $\mathrm{q} 33.1$ & 50 & 0.001 \\
\hline & $\mathrm{CN}$ gain & chr5:172,100,206-172,250,021 & $\mathrm{q} 35.1-\mathrm{q} 35.2$ & 50 & 0.001 \\
\hline & $\mathrm{CN}$ gain & chr6:26,128,335-26,352,388 & $\mathrm{p} 22.1$ & 66.7 & 0.004 \\
\hline & $\mathrm{CN}$ gain & chr8:134,026,676-134,089,398 & $\mathrm{q} 24.22$ & 58.3 & 0 \\
\hline & $\mathrm{CN}$ gain & chr9:43,997,314-44,825,192 & $\mathrm{p} 11.2$ & 50 & 0 \\
\hline & CN loss & chr10:133,727,624-135,374,737 & $\mathrm{q} 26.3$ & 41.7 & 0.026 \\
\hline & $\mathrm{CN}$ gain & $\operatorname{chr11:35,117,949-35,240,617}$ & p13 & 41.7 & 0 \\
\hline & $\mathrm{CN}$ gain & $\operatorname{chr} 15: 83,849,162-83,995,470$ & $\mathrm{q} 25.3$ & 41.7 & 0 \\
\hline & $\mathrm{CN}$ gain & $\operatorname{chr} 17: 45,586,978-45,621,111$ & $\mathrm{q} 21.33$ & 50 & 0.015 \\
\hline & $\mathrm{CN}$ gain & $\operatorname{chr} 17: 55,139,289-55,290,700$ & $\mathrm{q} 23.1$ & 50 & 0.015 \\
\hline & CN loss & chr22:47,207,744-47,732,937 & $\mathrm{q} 13.32$ & 50 & 0 \\
\hline \multirow{3}{*}{$\begin{array}{l}\text { Squamous cell } \\
\text { carcinoma }(n=6)\end{array}$} & $\mathrm{CN}$ gain & chr4:87,398,382-87,491,412 & $\mathrm{q} 21.3$ & 50 & 0.028 \\
\hline & CN loss & chr9:139,183,759-140,273,252 & $\mathrm{q} 34.3$ & 66.7 & 0.042 \\
\hline & $\mathrm{CN}$ gain & chr12:74,190,395-74,668,717 & $\mathrm{q} 21.2$ & 66.7 & 0.026 \\
\hline
\end{tabular}

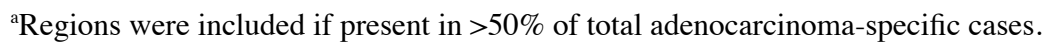

Table III. The comparison of recurrent copy number alterations in primary lung adenocarcinomas derived from the patients with synchronous $(n=4)$ and metachronous $(n=8)$ brain metastasis.

\begin{tabular}{lllllllll}
\hline Event & $\begin{array}{c}\text { Chromosome } \\
\text { cytoband }\end{array}$ & Start & End & $\begin{array}{c}\text { Region } \\
\text { length }\end{array}$ & Genes & $\begin{array}{c}\text { Frequency \% } \\
\text { synchronous BM } \\
\text { (Total cases = 8) }\end{array}$ & $\begin{array}{c}\text { Frequency \% BM } \\
\text { metachronous } \\
\text { (Total cases = 4) }\end{array}$ & $\begin{array}{c}\text { P-value } \\
\text { Gain }\end{array}$ \\
& $5 \mathrm{q} 35.1$ & 172008530 & 172100206 & 91,676 & NeurL1B & 100 & 12.5 & 0.01 \\
& $5 \mathrm{q} 35.2$ & 172250021 & 172277415 & 27394 & ERGIC1 & 100 & 12.5 & 0.01 \\
& $10 \mathrm{q} 23.31$ & 90682710 & 90735753 & 53043 & ACTA2 & 75 & 0 & 0.018 \\
& $10 \mathrm{q} 23.31$ & 90749267 & 90751025 & 1758 & FAS & 75 & 0 & 0.018 \\
& $17 \mathrm{q} 23.3$ & 59424619 & 59455000 & 30381 & C17orf72, ICAM2 & 100 & 0 & 0.002 \\
& $17 \mathrm{q} 24.1$ & 60155862 & 60203841 & 47979 & LOC146880 & 100 & 12.5 & 0.01 \\
& $17 \mathrm{q} 24.1$ & 60635140 & 60665382 & 30242 & RGS9 & 75 & 0 & 0.018 \\
\hline
\end{tabular}

${ }^{\mathrm{a}} \mathrm{BM}$, brain metastasis.

mediate or impede metastatic progression without affecting primary malignancy (26). When patterns of CNAs in $11 \mathrm{BM}$ (8 ADCs and 3 SQCCs) were compared with those of corresponding primary lung tumors, BM were found to carry the majority of genetic alterations present in the corresponding primary tumors (data not shown). However, in ADCs, BM harbored specific CNAs; new 11p and 15q gain (data not shown). In SQCCs, no BM specific CNAs were detected, likely because of the small number $(n=3)$ of the SQCC cases. Therefore, BM specific CNAs were further analyzed in the ADCs.

Genetic signatures associated with early brain metastasis of lung adenocarcinoma. Although comparing the genetic alterations between primary and metastatic tumor would have functional implications, BM-associated genetic signatures in the primary lung ADC would have been more clinically relevant. Lung ADC is characterized by the early development of BM and the incidence of BM based on autopsy findings was as high as $50 \%$ in patients with lung $\operatorname{ADC}(8,27)$. Given that BM significantly worsens prognosis of lung ADC patients, lung ADC patients who are likely to develop BM need adjuvant treatments for BM. Primary lung ADCs with early development of BM (synchronous) would contain more CNAs predictive of metastatic potential or aggressive transformation. To uncover complex genetic 'signatures' that can predict the risk of BM, the copy number changes of 4 lung ADCs with 
synchronous BM were compared with those of 8 lung ADCs with metachronous BM (Table III and Fig. 2). Amplification in 5q35.1-2, 10q23.31, 17q23.3-24.1 and 17q24.1 was detected in $100,75,100$ and $75 \%$ of the cases with synchronous BM, respectively, significantly more frequent than that of lung ADCs with metachronous BM (Table III). Differentially gained regions between primary ADCs with synchronous and metachronous BM were found to contain putative metastasis promoting genes, NeurL1B, ACTA2, FAS and ICAM2 (Table III).

\section{Discussion}

Although the BM affecting up to $25 \%$ of NSCLC during their lifetime negatively impacts survival, currently, there are no standard practice measures to reduce BM risk in NSCLC $(28,29)$. Under the hypothesis that the genes residing in amplified or deleted regions in each subtype play an important role in the histology-specific pathogenesis of NSCLC, this study was designed to identify 'meta-signatures' that stratify NSCLC patients at higher risk for BM. The NSCLC harbours several histopathologically and molecularly distinct subtypes including ADC and SQCC. However, important molecular differences between primary lung ADC and SQCC have been identified, suggesting that future targeted therapies need to be histology-specific $(8,16,17,30-36)$. For example, KRAS and epidermal growth factor receptor (EGFR) gene mutations are found almost exclusively in ADCs rather than SQCCs. Therefore, primary lung ADCs were separately analyzed in this study.

Due to increasing incidence and substantial relapse rate, the pattern of CNAs was compared between primary ADCs derived from patients with synchronous and metachronous $\mathrm{BM}$ to find brain-specific meta-signature and putative targets associated with BM in ADC subtype. Several putative genes reported to be involved in tumorigenesis of various cancers were demonstrated in our study. For example, Neuralized-1B is the E3 ubiquitin ligase that is required for endocytosis regulating both the receptor and ligand side in Notch signaling $(37,38)$. Relatively frequent deregulation of the Notch pathway and Notch ligand Jagged $2 / \mathrm{miR}$ 200-dependent pathway in NSCLC indicates the significance and mechanisms underpinning Notch pathway activation in lung cancer (39-41). In addition, Fas signalling exhibits tumor-promoting effects by increasing proliferation and invasiveness (42-46). Fas can promote lung cancer growth by recruiting MDSC via cancer cell-derived PGE2 and signal for cell invasion via the glycogen synthase kinase $3 \beta$ pathway $(47,48)$. Human smooth muscle $\alpha$-actin (SMA/ACTA2) has been used as one of mesenchymal cell-specific markers showing the epithelial-to-myofibroblast transition involving actin-skeleton remodeling and myogenic reprogramming. The appearance of dot-like $\alpha$-SMA staining in cytokeratin positive cells may indicate the initial phase of the epithelial to mesenchymal transition (EMT) (49-54). Finally, a recent study reported ICAM2 as a mediator for a survival signal sufficient to block apoptosis by activation of the PI3K/AKT pathway (55). As tumor progression and response to treatment are determined by numerous co-dependent prognostic factors, a multi-genetic approach to determining the optimal treatment for individual patients is more likely to be successful rather than a single prognostic biomarker.

Evidence that highly metastatic clones from primary tumor had a higher rate of genetic mutability than non-metastatic clones from the same tumor provided an early link between metastasis and intrinsic genetic instability such as mutations and chromosomal rearrangements (56). Although several highthroughput technologies have been developed to detect genomic CNAs in a variety of cancers until recently, high sensitivity to detect single copy number changes and the ability to test FFPE samples in which DNA is known to be degraded to different degrees is important (12). Analyzing FFPE samples allows the utilization of the vast majority of cancer samples since most cancer tissue samples are available as FFPE. For our FFPE NSCLC samples, the MIP technology was used, which has been validated to be able to substitute aCGH $(12-15,57,58)$. Because MIP uses probes that have a genomic footprint of $\sim 40 \mathrm{bp}$, this high density platform only requires small amounts of DNA and, consequently, is well-suited for the analysis of degraded DNA in FFPE tissues (59). The results of this study using the MIP technique showed differential genetic alteration between lung ADCs and SQCCs, correlating well with previous studies using $\mathrm{aCGH}$. The similarities support the validity of the technique and the results from it. However, due to inadequate amount of extracted gDNA, quantitative-real-time-PCR (qRT-PCR) to validate copy number alterations identified by the MIP array could not be performed in our study.

In this study, we identified several genes associated with early BM of lung ADCs. Although our data suggested a new aspect of genomic alterations associated with BM of NSCLC, further biological studies to validate the role of identified candidates in brain-specific metastasis and testing the predictive power of our meta-signature in larger NSCLC samples would be required. In spite of several limitations of our study including very small number of NSCLC samples and absence of validation studies such as qRT-PCR, these genomic signatures may help to generate useful markers to refine prognosis and guide therapeutic decisions for improvement of prognosis and quality of life for patients with NSCLC.

\section{Acknowledgements}

This study was supported by a grant of the Korea Healthcare Technology R\&D Project, Ministry for Health and Welfare Affairs, Republic of Korea (A092255).

\section{References}

1. Choi YW, Choi JS, Zheng LT, et al: Comparative genomic hybridization array analysis and real time PCR reveals genomic alterations in squamous cell carcinomas of the lung. Lung Cancer 55: 43-51, 2007.

2. Travis WD, Brambilla E, Muller-Hermelink HK and Harris CC (eds): World Health Organization Classification of Tumors. Pathology and Genetics of the Lung, Pleura, Thymus and Heart. IARC Press, Lyon, 2004.

3. Spira A and Ettinger DS: Multidisciplinary management of lung cancer. N Engl J Med 350: 379-392, 2004.

4. Salgia R, Hensing T, Campbell N, et al: Personalized treatment of lung cancer. Semin Oncol 38: 274-283, 2011.

5. Parkin DM, Bray FI and Devesa SS: Cancer burden in the year 2000. The global picture. Eur J Cancer 37 (Suppl 8): S4-S66, 2001. 
6. Jemal A, Siegel R, Ward E, Hao Y, Xu J and Thun MJ: Cancer statistics, 2009. CA Cancer J Clin 59: 225-249, 2009.

7. Moran C: Importance of molecular features of non-small cell lung cancer for choice of treatment. Am J Pathol 178: 1940-1948, 2011.

8. Hoffman PC, Mauer AM and Vokes EE: Lung cancer. Lancet 355: 479-485, 2000.

9. Hess KR, Varadhachary GR, Taylor SH, et al: Metastatic patterns in adenocarcinoma. Cancer 106: 1624-1633, 2006.

10. Feld R, Rubinstein LV and Weisenberger TH: Sites of recurrence in resected stage I non-small-cell lung cancer: a guide for future studies. J Clin Oncol 2: 1352-1358, 1984.

11. Bernards R and Weinberg RA: A progression puzzle. Nature 418 : $823,2002$.

12. Wang Y, Moorhead M, Karlin-Neumann G, et al: Allele quantification using molecular inversion probes (MIP). Nucleic Acids Res 33: e183, 2005.

13. Johnson CE, Gorringe KL, Thompson ER, et al: Identification of copy number alterations associated with the progression of DCIS to invasive ductal carcinoma. Breast Cancer Res Treat 133 889-898, 2011.

14. Schiffman JD, Wang Y, McPherson LA, et al: Molecular inversion probes reveal patterns of 9p21 deletion and copy number aberrations in childhood leukemia. Cancer Genet Cytogenet 193: 9-18, 2009.

15. Wang Y, Moorhead M, Karlin-Neumann G, et al: Analysis of molecular inversion probe performance for allele copy number determination. Genome Biol 8: R246, 2007.

16. Travis WD and Rekhtman N: Pathological diagnosis and classification of lung cancer in small biopsies and cytology: strategic management of tissue for molecular testing. Semin Respir Crit Care Med 32: 22-31, 2011.

17. Travis WD, Rekhtman N, Riley GJ, et al: Pathologic diagnosis of advanced lung cancer based on small biopsies and cytology: a paradigm shift. J Thorac Oncol 5: 411-414, 2010.

18. Kang JU, Koo SH, Kwon KC, Park JW and Kim JM: Identification of novel candidate target genes, including EPHB3, MASP1 and SST at 3q26.2-q29 in squamous cell carcinoma of the lung. BMC Cancer 9: 237, 2009

19. Yokoi S, Yasui K, Iizasa T, Imoto I, Fujisawa T and Inazawa J: TERC identified as a probable target within the $3 \mathrm{q} 26$ amplicon that is detected frequently in non-small cell lung cancers. Clin Cancer Res 9: 4705-4713, 2003.

20. Ubagai T, Matsuura S, Tauchi H, Itou K and Komatsu K: Comparative genomic hybridization analysis suggests a gain of chromosome $7 \mathrm{p}$ associated with lymph node metastasis in non-small cell lung cancer. Oncol Rep 8: 83-88, 2001.

21. Kang JU KS, Kwon KC, Park JW, Shin SY, Kim JM and Jung SS: High frequency of genetic alterations in non-small cell lung cancer detected by multi-target fluorescence in situ hybridization. J Korean Med Sci 22: 47-51, 2007.

22. Dehan E, Ben-Dor A, Liao W, et al: Chromosomal aberrations and gene expression profiles in non-small cell lung cancer. Lung Cancer 56: 175-184, 2007.

23. Chujo M, Noguchi T, Miura T, Arinaga M, Uchida Y and Tagawa Y: Comparative genomic hybridization analysis detected frequent overrepresentation of chromosome $3 q$ in squamous cell carcinoma of the lung. Lung Cancer 38: 23-29, 2002.

24. Kang JU, Koo SH, Kwon KC, Park JW and Jung SS: Gain of the EGFR gene located on $7 \mathrm{p} 12$ is a frequent and early event in squamous cell carcinoma of the lung. Cancer Genet Cytogenet 184: 31-37, 2008

25. Massion PP, Kuo WL, Stokoe D, et al: Genomic copy number analysis of non-small cell lung cancer using array comparative genomic hybridization: implications of the phosphatidylinositol 3-kinase pathway. Cancer Res 62: 3636-3640, 2002

26. Kikuchi T, Daigo Y, Ishikawa N, et al: Expression profiles of metastatic brain tumor from lung adenocarcinomas on cDNA microarray. Int J Oncol 28: 799-805, 2006.

27. Robnett TJ, Machtay M, Stevenson JP, Algazy KM and Hahn SM: Factors affecting the risk of brain metastases after definitive chemoradiation for locally advanced non-small-cell lung carcinoma. J Clin Oncol 19: 1344-1349, 2001.

28. Grinberg-Rashi H, Ofek E, Perelman M, et al: The expression of three genes in primary non-small cell lung cancer is associated with metastatic spread to the brain. Clin Cancer Res 15: 1755-1761, 2009.

29. Oh Y, Taylor S, Bekele BN, et al: Number of metastatic sites is a strong predictor of survival in patients with nonsmall cell lung cancer with or without brain metastases. Cancer 115: 2930-2938, 2009.
30. Tam IY, Chung LP, Suen WS, et al: Distinct epidermal growth factor receptor and KRAS mutation patterns in non-small cell lung cancer patients with different tobacco exposure and clinicopathologic features. Clin Cancer Res 12: 1647-1653, 2006.

31. Mok TS, Wu YL, Thongprasert S, et al: Gefitinib or carboplatinpaclitaxel in pulmonary adenocarcinoma. N Engl J Med 361: 947-957, 2009.

32. Shaw AT, Yeap BY, Mino-Kenudson M, et al: Clinical features and outcome of patients with non-small-cell lung cancer who harbor EML4-ALK. J Clin Oncol 27: 4247-4253, 2009.

33. Scagliotti G, Brodowicz T, Shepherd FA, et al: Treatment-byhistology interaction analyses in three phase III trials show superiority of pemetrexed in nonsquamous non-small cell lung cancer. J Thorac Oncol 6: 64-70, 2011.

34. Chansky K, Sculier JP, Crowley JJ, Giroux D, Van Meerbeeck J and Goldstraw P: The International Association for the Study of Lung Cancer Staging Project: prognostic factors and pathologic TNM stage in surgically managed non-small cell lung cancer. J Thorac Oncol 4: 792-801, 2009.

35. Pisters KM, Evans WK, Azzoli CG, et al: Cancer Care Ontario and American Society of Clinical Oncology adjuvant chemotherapy and adjuvant radiation therapy for stages I-IIIA resectable non-small-cell lung cancer guideline. J Clin Oncol 25 5506-5518, 2007

36. Bass AJ, Watanabe $\mathrm{H}$, Mermel $\mathrm{CH}$, et al: SOX2 is an amplified lineage-survival oncogene in lung and esophageal squamous cell carcinomas. Nat Genet 41: 1238-1242, 2009.

37. Rullinkov G, Tamme R, Sarapuu A, et al: Neuralized-2: expression in human and rodents and interaction with Delta-like ligands. Biochem Biophys Res Commun 389: 420-425, 2009.

38. Song R, Koo BK, Yoon KJ, et al: Neuralized-2 regulates a Notch ligand in cooperation with Mind bomb-1. J Biol Chem 281: 36391-36400, 2006.

39. Collins BJ, Kleeberger W and Ball DW: Notch in lung development and lung cancer. Semin Cancer Biol 14: 357-364, 2004.

40. Westhoff B, Colaluca IN, D'Ario G, et al: Alterations of the Notch pathway in lung cancer. Proc Natl Acad Sci USA 106 22293-22298, 2009.

41. Yang Y, Ahn YH, Gibbons DL, et al: The Notch ligand Jagged2 promotes lung adenocarcinoma metastasis through a miR200-dependent pathway in mice. J Clin Invest 121: 1373-1385, 2011.

42. Peter ME, Budd RC, Desbarats J, et al: The CD95 receptor: apoptosis revisited. Cell 129: 447-450, 2007.

43. Peter ME, Legembre P and Barnhart BC: Does CD95 have tumor promoting activities? Biochim Biophys Acta 1755: 25-36, 2005.

44. Mitsiades CS, Poulaki V, Fanourakis G, et al: Fas signaling in thyroid carcinomas is diverted from apoptosis to proliferation. Clin Cancer Res 12: 3705-3712, 2006.

45. Barnhart BC, Legembre P, Pietras E, Bubici C, Franzoso G and Peter ME: CD95 ligand induces motility and invasiveness of apoptosis-resistant tumor cells. EMBO J 23: 3175-3185, 2004

46. Chen L, Park SM, Tumanov AV, et al: CD95 promotes tumour growth. Nature 465: 492-496, 2010.

47. Zhang Y, Liu Q, Zhang M, Yu Y, Liu X and Cao X: Fas signal promotes lung cancer growth by recruiting myeloid-derived suppressor cells via cancer cell-derived PGE2. J Immunol 182: 3801-3808, 2009.

48. Kleber S, Sancho-Martinez I, Wiestler B, et al: Yes and PI3K bind CD95 to signal invasion of glioblastoma. Cancer Cell 13: 235-248, 2008

49. Masszi A, Speight P, Charbonney E, et al: Fate-determining mechanisms in epithelial-myofibroblast transition: major inhibitory role for Smad3. J Cell Biol 188: 383-399, 2010.

50. Wang J, Zohar R and McCulloch CA: Multiple roles of alphasmooth muscle actin in mechanotransduction. Exp Cell Res 312: 205-214, 2006

51. Han M, Liu M, Wang Y, et al: Re-expression of miR-21 contributes to migration and invasion by inducing epithelial-mesenchymal transition consistent with cancer stem cell characteristics in MCF-7 cells. Mol Cell Biochem 363: 427-436, 2012

52. Owens GK and Thompson MM: Developmental changes in isoactin expression in rat aortic smooth muscle cells in vivo. Relationship between growth and cytodifferentiation. J Biol Chem 261: 13373-13380, 1986.

53. Pirozzi G, Tirino V, Camerlingo R, et al: Epithelial to mesenchymal transition by TGFbeta-1 induction increases stemness characteristics in primary non-small cell lung cancer cell line. PLoS One 6: e21548, 2011. 
54. Valcz G, Sipos F, Krenacs T, et al: Increase of alpha-SMA(+) and $\mathrm{CK}(+)$ cells as an early sign of epithelial-mesenchymal transition during colorectal carcinogenesis. Pathol Oncol Res 18: 371-376, 2012.

55. Perez OD, Kinoshita S, Hitoshi Y, et al: Activation of the PKB/ AKT pathway by ICAM-2. Immunity 16: 51-65, 2002.

56. Fidler IJ: The pathogenesis of cancer metastasis: the 'seed and soil' hypothesis revisited. Nat Rev Cancer 3: 453-458, 2003.

57. Ji H, Kumm J, Zhang M, et al: Molecular inversion probe analysis of gene copy alterations reveals distinct categories of colorectal carcinoma. Cancer Res 66: 7910-7919, 2006.
58. Lapuk A, Volik S, Vincent R, et al: Computational BAC clone contig assembly for comprehensive genome analysis. Genes Chromosomes Cancer 40: 66-71, 2004.

59. Wang Y, Carlton VE, Karlin-Neumann G, et al: High quality copy number and genotype data from FFPE samples using Molecular Inversion Probe (MIP) microarrays. BMC Med Genomics 2: 8 , 2009. 